\title{
An unusual case of delivery with central rupture of perineum and intact introitus
}

\author{
Priyanka Mathe $^{1 *}$, Manisha Meena ${ }^{1}$, Rekha Bharti²
}

${ }^{1}$ Department of Obstetrics and Gynaecology, ESIC medical college and hospital, Faridabad, Haryana, India

${ }^{2}$ Department of Obstetrics and Gynaecology, VMMC and Safdarjung Hospital, New Delhi, Delhi, India

Received: 19 March 2019

Accepted: 04 May 2019

\author{
*Correspondence: \\ Dr. Priyanka Mathe, \\ E-mail: priyankamathe23@gmail.com
}

Copyright: () the author(s), publisher and licensee Medip Academy. This is an open-access article distributed under the terms of the Creative Commons Attribution Non-Commercial License, which permits unrestricted non-commercial use, distribution, and reproduction in any medium, provided the original work is properly cited.

\begin{abstract}
Most women experience some degree of tear during childbirth and in some these can be extensive. Obstetrics injuries contribute $0.5-15 \%$ of vaginal deliveries. Here authors present a case of 23 -year-old primigravida who presented at Safdarjung hospital New Delhi, Delhi, India with complaint of pain in perineum and excessive bleeding per vaginum. On examination, introitus was intact and there was central rupture of perineum which involved anal sphincter proximally and rectal mucosa distally. Patient was shifted to operation theatre for exploration and repair. She received 2 units of blood transfusion, antibiotics and laxatives. Patient was discharged on post-operative day 5 in satisfactory condition. Thus, authors emphasise the need of institutional delivery and prevention of perineal injuries which would further obviate the need for surgical repair and associated morbidity. In present era of easy communication and transport we still receive cases of unsupervised deliveries which gives us a strong motive to spread awareness for antenatal visits and care among this population.
\end{abstract}

Keywords: Fecal incontinence, Obstetric anal sphincter injuries, Perineal tear, Perineal rupture

\section{INTRODUCTION}

Obstetric anal sphincter injuries (OASIS) are the injuries to anal sphincter complex, which are uncommon but serious complications of vaginal birth. WHO International Consultation on Incontinence defines anal incontinence as the involuntary loss of flatus, liquid or solid stool that is a social or hygienic problem. ${ }^{1}$ Obstetric injuries during childbirth can damage both physical and mental well-being of the patient. Although most women sustain some degree of perineal trauma during vaginal birth, the incidence vary between $0.25 \%-24.5 \%$. The incidence of injuries to anal sphincter is nearly $3 \%$ during vaginal births. ${ }^{2,3}$ Most severe form of obstetric injuries like $3^{\text {rd }}$ and $4^{\text {th }}$ degree perineal tears have been associated with multiple adverse maternal and postpartum outcomes like wound infections and breakdown, perineal pain, dyspareunia, sexual dysfunction, anal and urinary incontinence and associated with overall diminished quality of life., ${ }^{4,5}$ Anal incontinence can be due to either direct mechanical trauma or neurological injury, although isolated neurological injuries are uncommon. Direct mechanical injury during labour to external anal sphincter and/or internal anal sphincter is major cause of anal incontinence. ${ }^{6}$ Therefore, timely diagnosis and management of these injuries can reduce short- and longterm morbidities to a greater extent.

\section{CASE REPORT}

A 23 years old unbooked and uninvestigated primigravida presented to Safdarjung hospital with complaints of pain in perineal area and excessive bleeding through perineum. She had an unsupervised 
spontaneous home delivery in standing position after which she delivered a still born baby. She presented to us 2 hours after delivery.

On general examination she was well oriented to time, place and person. She was afebrile. Moderate pallor was present. No signs of pedal oedema, clubbing, cyanosis or lymphadenopathy. Respiratory rate was $14 / \mathrm{mins}$ and pulse rate were $102 / \mathrm{min}$ with blood pressure of $100 / 70$ $\mathrm{mm} \mathrm{Hg}$. On per abdomen examination, abdomen was soft, non-tender and all quadrants were moving well with respiration. Uterus was well contracted.

On local examination Introitus was intact. A vaginal mucosal tear approximately $2 \times 4 \mathrm{~cm}$ was present $3 \mathrm{~cm}$ above the Introitus and was communicating with $4 \times 6 \mathrm{~cm}$ perineal tear. The perineal tear was involving anterior fibres of anal sphincter and distal $2 \mathrm{cms}$ of anterior wall of rectal mucosa (Figure 1).

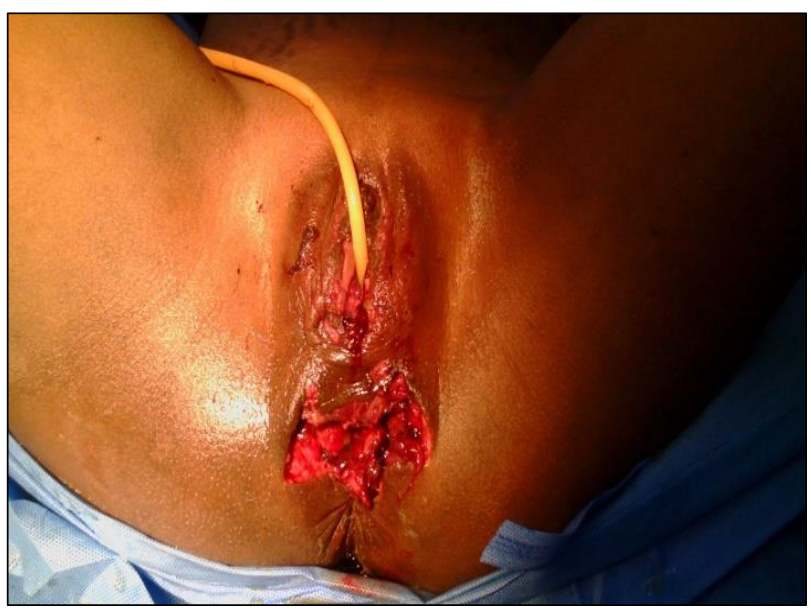

Figure 1: Central rupture of perineum with intact introitus.

After examination decision for tear repair under anaesthesia was taken. Relevant investigations including complete haemogram and platelet count with peripheral smear for type of anaemia, blood group for cross matching, coagulation profile, serum electrolytes, random blood sugar, urine for routine and microscopy were sent. Parenteral antibiotics were started and 2 units of packed cells were arranged. Patient was taken up for repair under regional anaesthesia. The bridging tissue of introitus was bisected followed by repair of complete perineal tear (Figure 2 and Figure 3). There was also a lateral tear which was sutured separately. Patient received 2 units of packed cells intraoperatively.

During post-operative period patient was orally allowed after 48 hours. Third generation antibiotic along with metronidazole and gentamycin were given for 5 days. Adequate antacid and analgesics were also given. Syrup lactulose was added as laxative so as to avoid stool straining. Per urethral catheter was removed after 24 hours and patient was discharged after 5 days in satisfactory condition.

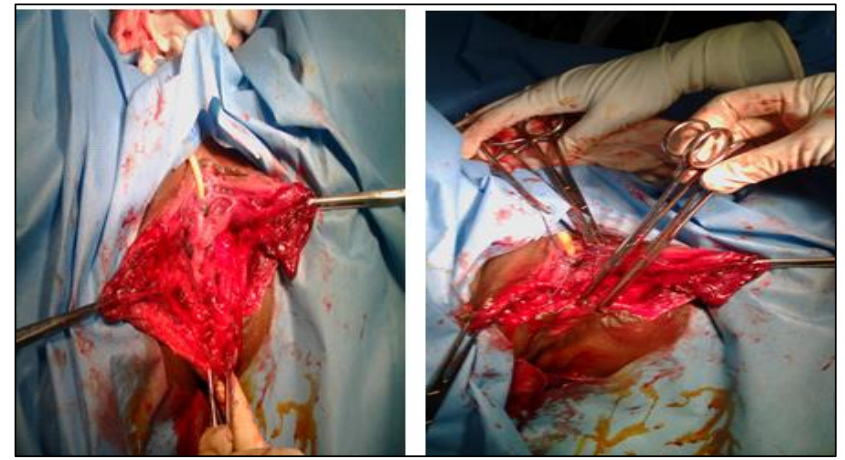

Figure 2,3: After bisection of bridging tissue repair of complete perineal tear.

\section{DISCUSSION}

Obstetric anal sphincter injuries are caused by perineal trauma during childbirth. Abbot et al, did a study on more than 20000 consecutive vaginal deliveries and found out that obstetric anal sphincter injuries occurred in $2.9 \%$ of primiparous women and $0.8 \%$ of multiparous ones. ${ }^{7}$ Risk factors for this include instrumental deliveries, prolonged second stage of labour, birth weight $>4 \mathrm{~kg}$, midline episiotomy, persistent occipito-posterior position of foetal head, precipitate labour, induction of labour, first vaginal birth. ${ }^{2,8}$

The following classification described by Sultan has been adopted by the International Consultation on Incontinence and the RCOG. ${ }^{9,10}$

- First-degree tear: Injury to perineal skin and/or vaginal mucosa.

- Second-degree tear: Injury to perineum involving perineal muscles but not involving the anal sphincter.

- Third-degree tear: Injury to perineum involving the anal sphincter complex.

- Grade 3a tear: Less than $50 \%$ of external anal sphincter (EAS) thickness torn.

- Grade 3b tear: More than 50\% of EAS thickness torn.

- Grade 3c tear: Both EAS and internal anal sphincter (IAS) torn.

- Fourth-degree tear: Injury to perineum involving the anal sphincter complex (EAS and IAS) and anorectal mucosa.

Anal incontinence is a debilitating disease. These injuries should be appropriately classified and repaired. Whenever in doubt, it is advisable to classify the tear to a higher degree than to a lower degree. These injuries may lead to both short term and long term morbidity, like perineal pain, prolapse, bowel incontinence, urinary incontinence, diminished sexual function, risk of tear in subsequent deliveries and diminished quality of life. Also, patients presenting late with fecal incontinence who have substantial sphincter disruption, elective repair can 
be attempted as results of primary and elective repair may deteriorate with time.

\section{CONCLUSION}

Thus, the high-risk females for these injuries should be identified and proactively managed so as to provide a better obstetric and neonatal outcome. Awareness regarding antenatal checkups and promotion of institutional deliveries should be ensured. Patients who have experienced severe obstetric injuries in previous delivery may be offered choice for caesarean section.

Funding: No funding sources Conflict of interest: None declared

Ethical approval: Not required

\section{REFERENCES}

1. Norton C, Whitehead W, Bliss DZ, Harari D, Lang J. Conservative and pharmacological management of faecal incontinence in adults. In: Abrams P, Cardozo L, Khoury S, Wein A, eds. Incontinence. Plymouth: Health Publications. 2009; 1321-86.

2. Sultan AH, Kamm MA, Hudson CN, Bartram CI. Third degree obstetric anal sphincter tears: Risk factors and outcome of primary repair. BMJ. 1994; 308:887-91.

3. Fornell EK, Berg G, Hallböök O, Matthiesen LS, Sjödahl R. Clinical consequences of anal sphincter rupture during vaginal delivery. J Am Coll Surg. 1996;183: 553-8.
4. Lewicky-Gaupp C, Leader-Cramer A, Johnson LL, Kenton K, Gossett DR. Obstet Gynecol. 2015;125(5):1088-93.

5. Haylen BT, Ridder DD, Freeman RM, Swift SE, Berghmans B, Lee $\mathrm{J}$, et al. International Urogynecological Association; International Continence Society. An International Urogynecological Association (IUGA)/International Continence Society (ICS) joint report on the terminology for female pelvic floor dysfunction. Neurourol Urodyn. 2010;29:4-20.

6. Sultan A, Nugent K. Pathophysiology and nonsurgical treatment of anal incontinence. BJOG. 2004;111(1):84-90.

7. Abbott D, Roberts AN, Williams A, Ntim OE, Chappell LC. Obstetric anal sphincter injury. BMJ. 2010;341:c3414.

8. Dudding TC, Vaizey CJ, Kamm MA. Obstetric anal sphincter injury: incidence, risk factors, and management. Ann Surg. 2008;247:224-37.

9. Sultan AH. Obstetric perineal injury and anal incontinence. Clin Risk. 1999;5:193-6.

10. Koelbl H, Igawa T, Salvatore S, Laterza RM, Lowry A, Sievert KD, et al. Pathophysiology of urinary incontinence, faecal incontinence and pelvic organ prolapse. Incontinence: Committee. 2013;4:261-359.

Cite this article as: Mathe P, Meena M, Bharti R. An unusual case of delivery with central rupture of perineum and intact introitus. Int $\mathbf{J}$ Reprod Contracept Obstet Gynecol 2019;8:2556-8. 